\title{
X-linked myopathy with excessive autophagy
}

INSERM

\section{Source}

INSERM. (1999). Orphanet: an online rare disease and orphan drug data base. $\underline{X-l i n k e d}$ myopathy with excessive autophagy. ORPHA:25980

X-linked myopathy with excessive autophagy is a childhood-onset X-linked myopathy characterised by slow progression of muscle weakness and unique histopathological findings. 